\title{
APROXIMAÇÕES DA PRAXIOLOGIA MOTRIZ COM O CONCEITO DE ORGANIZAÇÃO INTERNA NA BASE NACIONAL COMUM CURRICU- LAR - EDUCAÇÃO FÍSICA
}

\author{
João Francisco Magno Ribas \\ Universidade Federal de Santa Maria, Santa Maria, Rio Grande do Sul, Brasil. \\ Bruno Minuzzi Lanes \\ Universidade Federal de Santa Maria, Santa Maria, Rio Grande do Sul, Brasil. \\ Felipe Menezes Fagundes \\ Universidade Federal de Santa Maria, Santa Maria, Rio Grande do Sul, Brasil. \\ Lidiane Soares Bordinhão \\ Universidade Federal de Santa Maria, Santa Maria, Rio Grande do Sul, Brasil. \\ Natiele Follmann \\ Universidade Federal de Santa Maria, Santa Maria, Rio Grande do Sul, Brasil. \\ Raquel Valente de Oliveira \\ Universidade Federal de Santa Maria, Santa Maria, Rio Grande do Sul, Brasil. \\ Vagner Augusto de Oliveira Schmidt \\ Universidade Federal de Santa Maria, Santa Maria, Rio Grande do Sul, Brasil. \\ William Daniel Bitencourt \\ Universidade Federal de Santa Maria, Santa Maria, Rio Grande do Sul, Brasil.
}

\section{Resumo}

A Base Nacional Comum Curricular (BNCC) consiste no documento normativo que define o conjunto de conhecimentos constituintes da Educação Básica. Na BNCC, a disciplina de Educação Física encontra-se na Área das Linguagens e classifica as práticas corporais a partir de três elementos fundamentais: Movimento Corporal, Organização Interna e Produto Cultural. Neste estudo, objetiva-se realizar uma análise crítica do elemento Organização Interna das práticas corporais adotado na BNCC - Educação Física a partir do referencial da Praxiologia Motriz (PM), especialmente com base no conceito de Lógica Interna. Para tanto, realizou-se uma análise teórica a partir desse conceito, em relação ao elemento Organização Interna. Constatou-se que a Lógica Interna pode subsidiar esse elemento fundamental, com base em critérios da PM que sistematizam essas práticas corporais.

Palavras-chave: Lógica Interna. Currículo. Educação Física. Praxiologia Motriz. 


\title{
APPROACHES OF MOTOR PRAXIOLOGY WITH INTERNAL ORGANIZATION'S CONCEPT IN BASE NATIONAL COMMON NATIONAL CURRICULAR BASE - PHYSICAL EDUCATION
}

\begin{abstract}
The National Curricular Common Base (BNCC) consists of the normative document that defines the set of knowledge constituent of Basic Education. At BNCC, the discipline of Physical Education is in the Language Area and classifies the corporal practices from three fundamental elements: Body Movement, Internal Organization and Cultural Product. In this study, the objective was to perform a critical analysis of the Internal Organization element of the corporal practices adopted at BNCC - Physical Education from the reference of the Motor Praxiology (PM), especially based on the concept of Internal Logic. For that, a theoretical analysis was made from the concept of Internal Logic, in relation to the Internal Organization element. It was verified that the Internal Logic can subsidize this fundamental element, based on PM criteria that systematize these corporal practices.
\end{abstract}

Key words: Internal Logic. Curriculum. Physical Education. Motor Praxiology.

\section{APROXIMACIONES DE LA PRAXIOLOGÍA MOTRIZ CON EL CONCEPTO DE ORGANIZACIÓN INTERNA EN LA BASE NACIONAL COMÚN CURRICULAR - EDUCACIÓN FÍSICA}

\begin{abstract}
Resumen
La Base Nacional Común Curricular (BNCC) consiste en el documento normativo que define el conjunto de conocimientos constituyentes de la Educación Básica. En la BNCC, la disciplina de Educación Física se encuentra en el Área de los Lenguajes y clasifica las prácticas corporales a partir de tres elementos fundamentales: Movimientos Corporales, Organización Interna y Producto Cultural. En este estudio, se objetivó realizar un análisis crítico del elemento Organización Interna de las prácticas corporales adoptado en la BNCC - Educación Física a partir del referencial de la Praxiología Motriz (PM), especialmente con base en el concepto de Lógica Interna. Para ello, se realizó un análisis teórico a partir del concepto de Lógica Interna, en relación al elemento Organización Interna. Se constató que la Lógica Interna puede subsidiar ese elemento fundamental, sobre la base de criterios de la PM que sistematizan esas prácticas corporales.
\end{abstract}

Palabras claves: Lógica Interna. Currículo. Educación Física. Praxiología Motriz.

\section{Introdução}

A Base Nacional Comum Curricular (BNCC) é um documento normativo que define um conjunto de aprendizagens essenciais que todos os alunos devem desenvolver ao longo de cada etapa e modalidade da Educação Básica (BRASIL, 2018). Esse documento vem orientando mudanças em todos os contextos educativos, com o objetivo de qualificar o sistema educacional brasileiro. Optou-se por analisar os conhecimentos desse documento considerando sua relevância para a educação brasileira. Embora sua materialização tenha ocorrido recentemente, existe um marco histórico e legal que apontou para a necessidade de sua construção, conforme sistematizado na Figura 1. 
Figura 1 - Resumo dos marcos legais até a consolidação da BNCC.

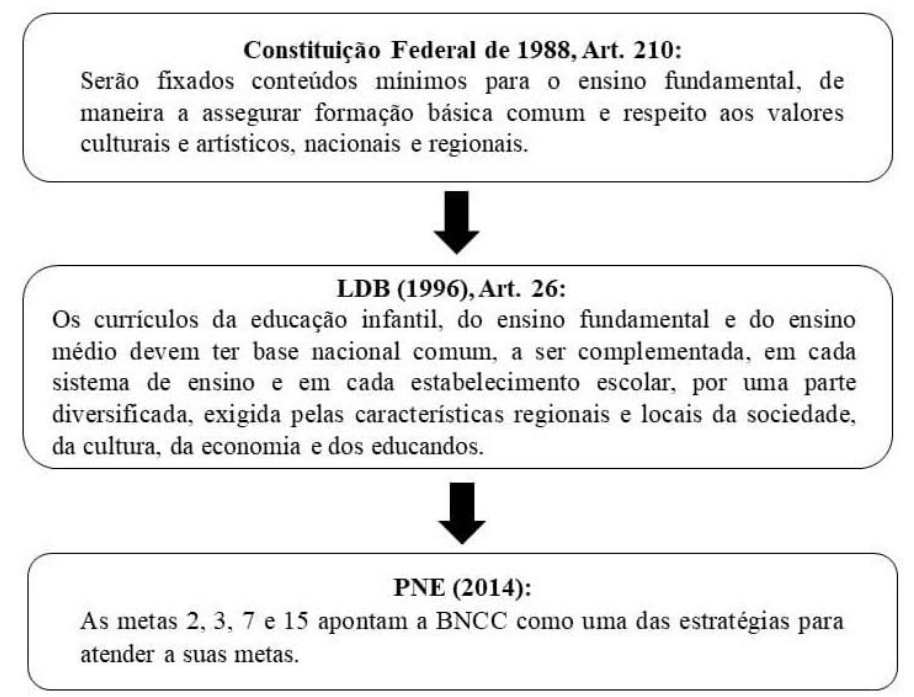

Fonte: Elaborado pelos autores.

As metas do Plano Nacional de Educação (PNE - 2014), mencionadas na figura acima, não fazem referência direta à base em seu texto. Contudo, a BNCC aparece como estratégia para a materialização daquelas metas, cada qual com sua especificidade. De acordo com Brasil (2018), a construção do documento da BNCC é o resultado de um processo amplo de debates e negociações com os diversos atores do campo educacional e, também, com a sociedade brasileira. O processo de elaboração do documento realizou-se da seguinte forma:

- Primeira versão: o documento foi disponibilizado à consulta pública de outubro de 2015 a março de 2016. Durante esse período, foram recebidas mais de 12 milhões de contribuições vindas de todo o país. As sugestões foram sistematizadas e utilizadas para a elaboração da segunda versão da proposta.

- Segunda Versão: em maio de 2016, essa versão foi debatida em seminários realizados pelas Secretarias Estaduais da Educação no período compreendido entre junho a agosto de 2016, sob a coordenação do Conselho Nacional de Secretários de Educação (Consed) e da União Nacional dos Dirigentes Municipais de Educação (Undime). Nessa etapa, participaram mais de nove mil professores, gestores, especialistas e entidades de educação e seus resultados foram sistematizados e organizados em um relatório.

- Versão Final: após análises e reformulações de sua sistematização, essa foi sancionada em março de 2018.

A versão final da BNCC foi analisada por um número mais restrito de especialistas do Brasil e também do exterior, em comparação à primeira versão. Os pareceres desses especialistas foram anexados ao relatório do Conseb/Undime e encaminhados ao Comitê Gestor da BNCC e Reforma do Ensino Médio, que é responsável pelas definições e diretrizes que orientaram a revisão da versão final e pela indicação dos especialistas que redigiram esse documento (BRASIL, 2018). Essa versão não explicitou a metodologia de escolha dos especialistas responsáveis por sua análise.

Neste sentido, com base em sua estruturação, acredita-se que a BNCC é um avanço para a sistematização dos conteúdos na Educação Básica em relação aos documentos anteriores, a exemplo dos Parâmetros Curriculares Nacionais. A definição dos conteúdos comuns 
consiste em um desafio, considerando a diversidade cultural brasileira. Com isso, salienta-se a necessidade de pesquisas em relação ao documento da BNCC, principalmente pelas instituições de ensino superior que são as responsáveis por formar professores para atuarem nesse nível de ensino.

Na BNCC, a disciplina de Educação Física encontra-se na Área das Linguagens e "tematiza as práticas corporais em suas diversas formas de codificação e significação social" (BRASIL, 2018, p. 211). Tais práticas corporais são classificadas, no documento, a partir de três elementos fundamentais: "Movimento corporal como elemento essencial; organização interna (de maior ou menor grau), pautada por uma lógica específica; e produto cultural vinculado com o lazer/entretenimento e/ou o cuidado com o corpo e a saúde" (BRASIL, 2018, p. 211).

A priori, constatou-se que o conceito de Organização Interna, pautado por uma lógica específica, aponta para o mesmo viés de estudo da Praxiologia Motriz (PM), área de conhecimento que possibilita estudar a Lógica Interna de jogos e esportes (PARLEBAS, 2001; LAGARDERA; LAVEGA, 2003). Nesse momento, a PM constitui-se no conhecimento científico que apresenta possibilidades concretas para o entendimento da Lógica Interna de todas as práticas motrizes pertencentes ao campo da Educação Física. A partir da aproximação entre esses dois conceitos, tem-se como problema de pesquisa: como a BNCC, em relação ao elemento Organização Interna das práticas corporais, estabelece relação com a Praxiologia Motriz, especificamente sobre o entendimento do conceito de Lógica Interna? Nesse sentido, objetivou-se realizar uma análise crítica do elemento Organização Interna das práticas corporais adotado na BNCC - Educação Física a partir do referencial da Praxiologia Motriz, especialmente com base no conceito de Lógica Interna.

Para tanto, foi realizada uma pesquisa teórica, que, segundo Demo (2000, p. 20), é "dedicada a reconstruir teorias, conceitos, ideias, ideologias, polêmicas, tendo em vista, em termos imediatos, aprimorar fundamentos teóricos". Além disso, para melhor compreensão de determinados termos contidos na BNCC - Educação Física, foram utilizadas definições conceituais e operacionais. Essa pesquisa restringiu-se à análise do elemento conceitual Organização Interna relativo à sistematização das práticas corporais da BNCC - Educação Física. De acordo com Richardson et al. (2011, p. 65), "a definição conceitual é considerada geral, ampla, enquanto a definição operacional é restrita, voltada diretamente para aspectos do objeto [...]". O autor destaca, ainda, que as "formas de conceituação podem levar não só ao processo de operacionalização de conceitos, como também ao processo de definição formal (literário) desses" (p. 65).

\section{Praxiologia motriz e lógica interna}

A Praxiologia Motriz é definida como Teoria da Ação Motriz que surge do conceito de "ato unidade", que liga o ator social e a ação como proposta de estudo da Sociologia. Esse conceito de "ato unidade" foi estruturado pelo sociólogo norte-americano Talcott Parsons que visava criar um objeto de estudo da Sociologia que viabilizasse uma ciência geral da ação social. Com base nesse entendimento, Pierre Parlebas elaborou o conceito de Ação Motriz com o intuito de estabelecer critérios de entendimento no campo da motricidade, sendo esse o objeto de estudo da Praxiologia Motriz (PARLEBAS, 2001).

A Ação Motriz, neste caso, seria um espaço social bem menos complexo que a Ação Social, no que tange a sua organização, já que se refere a uma situação social específica, no caso, o jogo esportivo ${ }^{1}$, bem como qualquer outra prática corporal. Além disso, Parlebas fez

1 Parlebas (2001, p. 276) define jogo esportivo como: "Situação de enfrentamento codificado, denominado jogo ou esporte pelas instâncias sociais. Cada jogo esportivo se define por um sistema de regras que determina sua 
um recorte ainda maior quando desenvolveu instrumentos de análise desse contexto social, visando a desvelar a Lógica Interna, evidenciando as Ações Motrizes que surgem a partir das regras das práticas corporais. Esse processo de análise praxiológica culmina com a elaboração da gramática das práticas corporais. Complementa-se essa ideia com as palavras de Serrano Sánchez (1996, p. 86):

Ainda que sua ordenação de gêneros tenha bases em conceitos psicossociais (cooperação, oposição, inter-relação com o meio físico) e socioculturais (institucionalização, regras, organização oficial, competição), a Ação Motriz só se explica pela sua lógica interna.

Mas, no que consiste essa Lógica Interna? Segundo Parlebas, Lógica Interna é o "sistema de características pertinentes de uma Situação Motriz e de suas implicações para a realização da ação motriz correspondente" (PARLEBAS, 1999, p. 302). Essa ideia indica que as formas de atuações em cada prática corporal estão previstas nas regras, ou seja, as ações motrizes ou as técnicas corporais surgem desse sistema regulamentar. As regras do jogo indicam o local, o material, o tempo e os modos de interação com o(s) objeto(s), espaço e, em alguns casos, com os outros participantes (companheiros e/ou adversários). Assim, as práticas corporais se constituem em manifestações culturais da humanidade, sistematizadas a partir de regras, sejam elas institucionalizadas ou não.

Nesse sentido, constatam-se possibilidades de aproximação entre o conceito de Lógica Interna e o elemento Organização Interna apresentado pela BNCC. Dessa forma, detalhou-se, na sequência, o entendimento sobre Organização Interna presente nesse documento.

\section{O elemento da organização interna das práticas corporais}

Ao compreender a BNCC como um documento de estruturação dos conteúdos da Educação Física, entende-se que o universo desse componente curricular contempla diversificados saberes corporais, experiências estéticas, emotivas e lúdicas, comumente orientadas em práticas pedagógicas na escola (BRASIL, 2018). Nessa perspectiva, é importante analisar as diferentes formas de expressão corporal, buscando estruturá-las de forma clara e propositiva. Com isso, a BNCC apresenta três elementos fundamentais das práticas corporais, sendo que este estudo deteve-se, exclusivamente, na Organização Interna.

Por se caracterizar como um elemento comum entre as práticas corporais apontadas pela BNCC, torna-se essencial o entendimento sobre Organização Interna. No entanto, esse documento não apresenta uma conceituação clara do elemento Organização Interna, deixando-o à mercê de diversas interpretações. Além disso, não foi encontrada a referida terminologia em nenhuma das obras consultadas para este estudo. Dessa forma, faz-se alguns questionamentos: por que não é apresentado uma definição teórica já que esse elemento é um pilar essencial para a compreensão da BNCC? Por que não apresentar referências para esse entendimento? A partir de que parâmetros teóricos o professor vai compreender esse elemento? Assim, torna-se necessário esclarecer de maneira mais específica esse conceito. A partir disso, apresenta-se a PM como uma alternativa de parâmetro teórico de sustentação para o elemento Organização Interna e, por essa razão, foram utilizados os termos conceituais para embasar as definições operacionais que serão propostas no decorrer das descrições.

Partindo dessa necessidade e dos questionamentos, buscou-se nos termos conceituais apresentar a definição de Organização Interna, utilizando o significado literal para introduzir os conceitos. Segundo o dicionário de português Aurélio (2017), a palavra "organização" re-

lógica”. Desse ponto em diante, será adotada a expressão prática corporal, a qual é utilizada na BNCC e que equivale às manifestações nela contidas. 
fere-se ao processo de estruturação do que se constitui em um sistema, uma arrumação. Além disso, define-se como a propriedade ou característica daquilo que se apresenta de modo organizado. No que diz respeito ao significado da palavra "interna", é remetido ao interior de algo, ou seja, o que está contido no espaço compreendido de um sistema (AURÉLIO, 2017). Dessa forma, entende-se Organização Interna como um processo que apresenta as características contidas em um sistema estruturado de maneira organizada.

Constatou-se também que, na BNCC, o elemento de Organização Interna caracterizase por estruturar as práticas corporais pautadas em uma lógica específica (BRASIL, 2018). Com base no conceito operacional, entende-se por lógica específica as principais características que interferem na Organização Interna de todas as práticas corporais, pois esse elemento apresenta princípios que processam as semelhanças e diferenças entre todas as estruturas dessas manifestações. Nessa perspectiva, entende-se como Organização Interna o elemento que sistematiza as principais características do funcionamento e estruturação das práticas corporais. Portanto, a forma como se sistematizam as regras, o material, as relações entre os praticantes, o espaço e o tempo, interferem no funcionamento dessas práticas corporais indicadas na BNCC. Dessa forma, é possível apresentar uma perspectiva que já se organiza de maneira mais estruturada em relação a esses conceitos.

Foi citado, anteriormente, que a PM apresenta subsídios que classificam e estruturam todas as práticas corporais a partir de suas características. Com o estudo da Lógica Interna das práticas motrizes, Parlebas (2001) elaborou ferramentas que permitem compreender o funcionamento dessas modalidades. Com esse pressuposto conceitual, observa-se que existem relações entre o elemento Organização Interna, adotado na BNCC, e o conceito de Lógica Interna proposto pela PM, articulação proposta a seguir.

\section{Proposições ao conceito de organização interna da BNCC a partir da lógica interna da PM}

Ao considerar que a BNCC (2018, p. 211) compreende que as práticas corporais são “[...] pautadas por uma lógica específica", parte-se do pressuposto de que todas essas práticas apresentam uma organização própria. Na concepção praxiológica, todas as manifestações esportivas ou lúdicas, compreendidas como sistemas praxiológicos, apresentam uma dinâmica de funcionamento intrínseca, unicamente a elas pertencentes (PARLEBAS, 2001; LAGARDERA; LAVEGA, 2003). Nesse sentido, entende-se que o elemento Organização Interna pode ser orientado a partir do conceito de Lógica Interna. Com essa proposição, a PM apresenta o Sistema de Classificação CAI, ferramenta que aponta critérios específicos da Lógica Interna para classificar as práticas motrizes.

O Sistema de Classificação CAI está estruturado com base nas interações motrizes estabelecidas com companheiros (C), com adversários (A) e com a incerteza do meio físico (I). Segundo Ribas (2014), essa ferramenta constitui-se como a primeira abordagem para o conhecimento da essência de uma prática corporal. Com esse panorama, as práticas motrizes podem ser classificadas de acordo com as interações motrizes estabelecidas em suas Lógicas Internas, como demonstrado na figura abaixo. 
Figura 2: Sistema de Classificação CAI.

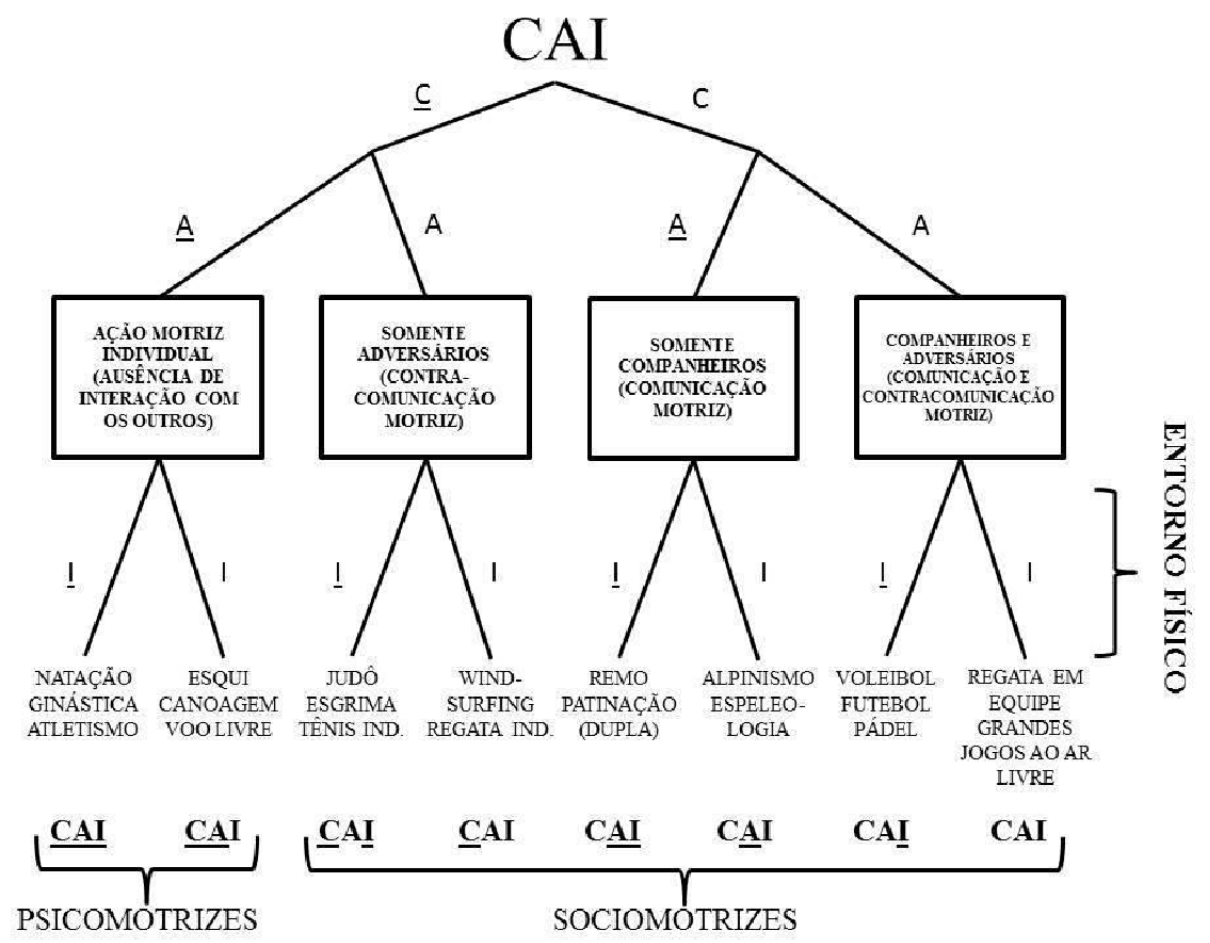

Fonte: Adaptada de Parlebas (2001).

No que se refere às interações motrizes, o Sistema de Classificação CAI apresenta dois grandes grupos: psicomotrizes e sociomotrizes. No grupo psicomotriz, estão as práticas nas quais os sujeitos não apresentam interação com outros participantes durante sua ação motriz, ou seja, não existe interação de oposição, nem de cooperação nessa categoria. No grupo sociomotriz, tem-se organizadas as práticas nas quais o sujeito interage com outros participantes. Nesse caso, as interações podem ser de cooperação, de oposição ou cooperação-oposição simultaneamente.

As práticas cooperativas têm suas Lógicas Internas pautadas pela interação de comunicação. Nessas práticas corporais, um ou mais participantes colaboram para um objetivo comum. Por outro lado, nas situações exclusivamente de oposição, as interações se realizam somente com adversário (LAGARDERA; LAVEGA, 2003). Essa oposição pode ser corporal ou de caráter instrumental, cuja oposição se realiza mediante um objeto extracorporal. Já nas práticas sociomotrizes de cooperação-oposição, os protagonistas atuam comunicando-se com companheiros e contracomunicando-se com adversários (LAGARDERA; LAVEGA, 2003).

No que se refere às possíveis incertezas do meio, a característica principal é a necessidade (ou não) de leitura do participante em relação ao entorno físico no qual a prática se realiza, apresentando dois tipos de situações: instável e estável. Tanto as práticas sociomotrizes quanto as psicomotrizes podem ou não apresentar incertezas do meio. O sujeito, quando em um entorno instável, deve interpretar suas alterações para o sucesso da prática motriz, a exemplo do Surfe, no qual o praticante deverá constantemente adaptar suas ações conforme as alterações do entorno físico (direção e velocidade do vento, temperatura da água, altura das ondas...). O contrário, segundo Lagardera e Lavega (2003), acontece quando as práticas se realizam num meio estável, no qual o protagonista não precisa se preocupar em tomar decisões em relação ao entorno físico. O Basquete é um exemplo de modalidade em contexto estável, pois as dimensões da quadra estão definidas nos regulamentos das competições e não se alteram no decorrer das práticas. 
Para Moreno (1998), a estrutura das atividades físicas e esportivas é um dos fatores determinantes no processo de ensino-aprendizagem, devendo, por isso, estabelecer-se uma classificação que permita caracterizar as diferentes práticas de acordo com sua Lógica Interna. Segundo Ribas (2014), Parlebas aponta que essa ordenação das práticas corporais supera os critérios tradicionais de classificação que, no seu entender, impedem sua visualização. A maioria das classificações, que se tem conhecimento, ajuda a compreender alguns aspectos dessas manifestações em relação ao material e ao local de prática, porém, no que tange à Lógica Interna dessas atividades, elas poderão se mostrar incoerentes. Parlebas (1988) reúne as sistematizações mais conhecidas das práticas corporais. São elas:

- Qualidades e atitudes que se consideram mais solicitadas pelos participantes. Ex.: esportes de força, de destreza, de resistência...

- Material e instrumentos utilizados: jogos de bola, de raquete, sob rodas...

- Local de prática: esportes ao ar livre, de pátio, de salão...

- Essência do meio de prática: esportes de neve, de praia, aéreos...

- Número de participantes: esporte individual, em duplas, coletivo...

- Outros critérios: motivações suscitadas, valor do espetáculo, complexidade dos gestos...

A classificação das práticas motrizes, orientada pela Lógica Interna, possibilitará ao professor organizar suas atividades e unidades temáticas (Brincadeiras e jogos; Esportes; Ginásticas; Danças; Lutas; Práticas corporais de aventura) sem tangenciar a lógica específica inerente à Organização Interna das práticas corporais. Tendo em vista a classificação empregada pela BNCC em relação à Organização Interna, evidencia-se que o conceito de Lógica Interna é citado apenas na unidade temática do Esporte. Dessa forma, identifica-se a carência de uma organização que contemple a Lógica Interna de todas as práticas motrizes, em suas respectivas unidades temáticas presentes na BNCC - Educação Física. Justifica-se isso à medida que todas as práticas motrizes possuam uma Lógica Interna própria, sendo algo não exclusivamente pertencente aos conteúdos que apresentem características do esporte institucionalizado. Por essa razão, torna-se necessário subdividir as seis unidades temáticas em categorias, de modo a organizá-las segundo suas Lógicas Internas.

Ao considerar especificamente o conceito de Lógica Interna, há um equívoco na categorização da unidade temática do Esporte. Identifica-se que suas categorias (Marca, Precisão, Técnico-combinatório, Rede/quadra dividida ou parede de rebote, Campo e taco, Invasão ou territorial e Combate) não apresentam um critério que agrupe de forma consistente as suas lógicas específicas (Lógicas Internas). Essa incoerência se dá pelo fato de que, para a organização dessa unidade temática, a BNCC apresentou como referência principal o desempenho motor, materiais e instrumentos utilizados, o local de prática e objetivos táticos das práticas corporais em detrimento das interações estabelecidas entre companheiros e adversários.

Desse modo, percebe-se esse equívoco, por exemplo, na categoria "Rede/quadra dividida ou parede de rebote", ao passo que o Voleibol e o Tênis foram contemplados no mesmo grupo. Corroborando isso, Fotia (2013) ressalta que, ao classificar o Voleibol como um esporte de quadra dividida e agrupá-lo com o Tênis, não se está considerando a Lógica Interna de ambas as práticas, uma vez que elas apresentam interações motrizes distintas. Além disso, o fato de ambos os campos serem separados por uma rede, a impossibilidade de reter a bola e de invadir o espaço do adversário durante o jogo não tornam essas práticas pertencentes a uma mesma categoria, referindo-se à Lógica Interna. Ainda, segundo Fotia (2013), a interação motriz com o material, as ações motrizes específicas de cada esporte, a maneira de rebater a bola, bem como a permissão ou não de quicá-la e as interações motrizes entre os jogadores são, 
evidentemente, distintas, tornando-se implausível sua distribuição em uma mesma categoria. Tendo em vista que a BNCC considera a Lógica Interna de interação entre participantes como um dos principais critérios de classificação, não seria mais coerente privilegiá-lo, nessa sistematização, em detrimento das características de espaço e material das práticas corporais?

Ao encontro disso, há também incoerência em outras categorias pertencentes à unidade temática do Esporte, ao ser considerado como critério apenas o objetivo tático dessas práticas motrizes, como nas categorias "Precisão" (Bocha, Golfe, Tiro com Arco) e "Invasão ou territorial" (Basquetebol, Futebol, Handebol, Pólo Aquático). Nesses exemplos, os elementos fundamentais da Lógica Interna foram considerados para o modelo de classificação, contudo, privilegiando, em alguns momentos, a relação com o espaço e com o material e, em outros, com o objetivo motor, o que dificulta a clareza da sistematização.

Desse modo, verifica-se a necessidade de um modelo de classificação coerente para agrupar as mais diferentes práticas corporais, tanto pertencentes ao esporte quanto às demais unidades temáticas dispostas na BNCC. Para isso, a PM, com o subsídio do Sistema de Classificação CAI, corrobora a sistematização dos conteúdos da Educação Física, conforme as interações motrizes estabelecidas na Lógica Interna das práticas motrizes, as quais estão organizadas no que diz respeito aos processos de leitura e interpretação dos jogadores e do entorno físico. A partir da proposta de Parlebas, têm-se férteis possibilidades de relação entre os conceitos praxiológicos e a prática pedagógica dos professores de Educação Física (RIBAS, 2016; DALLA NORA et al., 2016), uma vez que a PM, considerando o Sistema de Classificação CAI, apresenta contribuições ao arcabouço didático-metodológico dos professores.

A utilização do elemento fundamental Organização Interna na BNCC restringe-se, exclusivamente, ao critério de classificação, apresentando poucos subsídios didáticos para o ensino da lógica de funcionamento das práticas corporais. Essa limitação faz com que a BNCC perca seu caráter instrumental referente à materialização da atuação docente, levando os professores a debruçarem-se em outras literaturas para subsidiar suas práticas pedagógicas. Não se defende que a BNCC deveria apresentar-se como um manual, no entanto, o documento deveria indicar quais elementos dessa Organização Interna das práticas corporais são conhecimentos básicos a serem desenvolvidos, o que falta em sua estruturação. Além disso, a BNCC não apresenta nenhuma referência teórica, apenas identifica-se, pela similaridade das propostas, a influência dos estudos desenvolvidos por Gonzalez e colaboradores $(2012 ; 2014)$ na estruturação do documento, desamparando os professores no que se refere à busca de aprofundamento para o processo de ensino-aprendizagem.

Ao estruturar as práticas motrizes pelo Sistema de Classificação CAI, Parlebas (2001) já aponta indicações didático-metodológicas relevantes para o desenvolvimento dessas práticas. A (in)existência de cooperação e/ou oposição, facilitar ou dificultar ações de companheiros e/ou adversários, emitir mensagens claras ou obscuras sobre a sua atuação, bem como as interferências do meio nas ações motrizes são características intrínsecas à Lógica Interna das práticas e, consequentemente, elementos básicos para o desenvolvimento dessas manifestações.

Pode-se ilustrar essa proposição com um exemplo para o ensino do Tênis de Mesa individual. Ao considerá-lo como uma prática sociomotriz de oposição em meio padrão, elementos relevantes de sua Lógica Interna já são salientados, como dificultar ações e processos de leitura do adversário, despreocupação com as demandas do ambiente e constante emissão de mensagens obscuras. Essas características, fundamentais para sua dinâmica de funcionamento, devem estar presentes nas atividades propostas pelo professor de Educação Física, que visa a desenvolver as práticas motrizes com base em suas Lógicas Internas, pois são esses elementos que balizam e atrelam significado às ações motrizes dessa modalidade.

Essas peculiaridades das práticas sociomotrizes de oposição permeiam o âmbito global de entendimento de sua Lógica Interna. A materialização dessas características ocorre por 
meio das ações motrizes que estão diretamente relacionadas às regras das práticas corporais. Nesse sentido, é necessário considerar esses aspectos gerais, contudo, remetendo-os diretamente às regras específicas da prática em questão, as quais indicam suas ações motrizes.

A partir das discussões realizadas, nas quais se buscou articular o elemento fundamental Organização Interna com o conceito de Lógica Interna da PM, constatou-se que os conhecimentos praxiológicos podem subsidiar esse elemento, auxiliando o professor em seu trabalho docente. Portanto, considerando esses conhecimentos, o professor poderá articular o conceito de Lógica Interna em qualquer uma das unidades temáticas presentes na BNCC - Educação Física.

\section{Considerações Finais}

Ao considerar a Base Nacional Comum Curricular como um avanço para a Educação Física e constatando a necessidade de discussões referentes à estruturação dessa disciplina no referido documento, é que surgiu o interesse em realizar este estudo. Na BNCC, as práticas corporais estão classificadas com base em três elementos fundamentais: o Movimento Corporal, a Organização Interna e o Produto Cultural (BRASIL, 2018). Nessa investigação, o aprofundamento nos elementos de classificação das práticas corporais contidos no documento teve início pela Organização Interna, visto que, inicialmente, esse elemento remeteu a conceitos da Praxiologia Motriz. Portanto, o objetivo principal desta pesquisa foi realizar uma análise crít ica do elemento Organização Interna das práticas corporais adotado na BNCC - Educação Física a partir do referencial da Praxiologia Motriz (PM), especialmente com base no conceito de Lógica Interna.

A priori, constatou-se que não existem conceitos definidos do elemento de Organização Interna na BNCC e que não há menção às fontes ou referências teóricas utilizadas para a construção do documento. A indefinição quanto a esse conceito dá margem a diferentes interpretações. Nesse sentido, com base no significado literal, realizou-se, primeiramente, uma definição conceitual para esse elemento, que é entendido como um processo que apresenta as características contidas em um sistema estruturado de maneira organizada. Ainda, evidenciouse que a utilização do elemento fundamental Organização Interna restringe-se ao critério de classificação das práticas corporais, abordando poucas especificidades no que diz respeito a sua lógica de funcionamento. No entanto, a BNCC utiliza esse elemento apenas na classificação da unidade temática do Esporte, como se somente essa temática apresentasse diversas manifestações.

No que tange à Educação Física, a BNCC apresenta seis unidades temáticas: Brincadeiras e jogos, Esportes, Ginásticas, Danças, Lutas e Práticas corporais de aventura. Todavia, o documento apresenta limitações quanto à compreensão do significado do elemento Organização Interna e a sua relação com as práticas corporais. Portanto, constata-se a necessidade de adotar uma ferramenta que auxilie o professor no processo de ensino-aprendizagem, que considere e contemple a Lógica Interna de todas as práticas motrizes em suas respectivas unidades temáticas. Com esse sentido é que se apresenta a Praxiologia Motriz como possibilidade teórica de análise das práticas corporais, que, a partir do Sistema de Classificação CAI, apresenta inúmeras contribuições, entre elas os processos de leitura e interpretação dos jogadores e do entorno físico da prática no qual se está inserido.

Nessa perspectiva, as reflexões realizadas ao longo desse estudo não desconsideram todo o empenho, os avanços e as proposições indicadas na BNCC. A intenção da pesquisa não foi, em momento algum, menorizar a relevância do documento, pelo contrário, valoriza-se essa iniciativa, visto a carência de sistematização de conteúdos e a dificuldade desse processo para a área da Educação Física, considerando sua pluralidade. Por meio do Sistema de Classificação CAI, indicaram-se princípios de sistematização que implicam materialização de as- 
pectos didáticos diretamente relacionados ao conceito de Organização Interna das práticas corporais. O movimento realizado nesta análise almejou, portanto, contribuir na materialização dessa proposta para a prática pedagógica dos professores de Educação Física, considerando a Praxiologia Motriz.

\section{Referências}

AURÉLIO, Dicionário. Disponível em: https://dicionariodoaurelio.com/interna. Acesso em: 25 out. 2017.

AURÉLIO, Dicionário. Disponível em: https://dicionariodoaurelio.com/organizacao. Acesso em: 25 out. 2017.

BRASIL. Base Nacional Comum Curricular. Proposta preliminar. Segunda versão revista. Brasília, MEC, 2016. Disponível em: http://portal.mec.gov.br/dmdocuments/rceb007_10.pdf. Acesso em: 18 jul. 2017.

BRASIL. Constituição da república federativa do Brasil. Brasília, Senado, 1988.

BRASIL. Lei de Diretrizes e Bases da Educação. Brasília, DF, 1996.

BRASIL. Plano Nacional de Educação. Brasília, DF, 2014.

DALLA NORA, D. et al. Praxiologia Motriz, Trabalho Pedagógico e Didática na Educação Física. Movimento, v. 22, n. 4, 2016.

DEMO, P. Metodologia do Conhecimento Científico. São Paulo, Atlas, 2000.

FOTIA, J. Voleibol, lógica interna e iniciación. Acción Motriz, n. 10, p. 76-83, enero/jun. 2013. Disponível em: http://www.accionmotriz.com/documentos/revistas/articulos/10 6.pdf. Acesso em: 05 set. 2017.

GONZÁleS, F. J.; DARIDO, S. C.; OLIVEIRA, A. A. B. de. Coleção Práticas Corporais e a Organização do Conhecimento. Maringá, Eduem, 2014.

GONZÁLEZ, F. J.; BRACHT, V. Metodologia do ensino dos esportes coletivos. Vitória, UFES, Núcleo de Educação Aberta e a Distância, 2012.

LAGARDERA, F. O.; LAVEGA, P. B. Introducíon a la Praxiología Motriz. Barcelona, Editorial Paidotribo, 2003.

MORENO, J. H. Análisis de las Estructuras del Juego Deportivo. Inde Publicaciones, 1998.

PARLEBAS, P. Elementos de sociologia del deporte. Málaga: Colecion unisport- junta de Andalucia. 1988.

PARLEBAS, P. Juegos, deportes y sociedades: léxico de praxiología motriz. Madrid, Paidotribo, 2001. 
PARLEBAS, P. Jeux, sports et sociétés: lexique de praxéologie motrice. Paris, Insep, 1999.

RIBAS, J. F. M. (Org.) Praxiologia Motriz e Voleibol - elementos para o trabalho pedagógico. Ijuí, Editora UNIJUÍ, 2014.

RIBAS, J. F. M. Praxiologia Motriz e a Didática da Educação Física. In: KUNZ, Elenor. Didática da Educação Física - 4: Educação Física e Esportes na Escola. Ijuí, Unijuí; 2016. p. 129-151.

RICHARDSON, J. R. et al. Pesquisa social: métodos e técnicas. São Paulo, Atlas, 2011.

SERRANO SÁNCHES, J. A. Acerca de una confrontación de los problemas de estatuto científico entre la educación fisica y la praxiologia motriz. Revista de Praxiologia Motriz, Las Palmas de Gran Canárian, n. 0, v.1, p. 65-110. 1996.

Recebido em: 07/08/2018

Revisado em: 21/05/2019

Aprovado em: 15/07/2019

Endereço para correspondência:

felipemfagundes@live.com

Felipe Menezes Fagundes

Universidade Federal de Santa Maria

Centro de Educação Física e Desportos, Departamento de Desportos Coletivos.

Av. Roraima

Cidade Universitária

97119000 - Santa Maria, RS - Brasil 